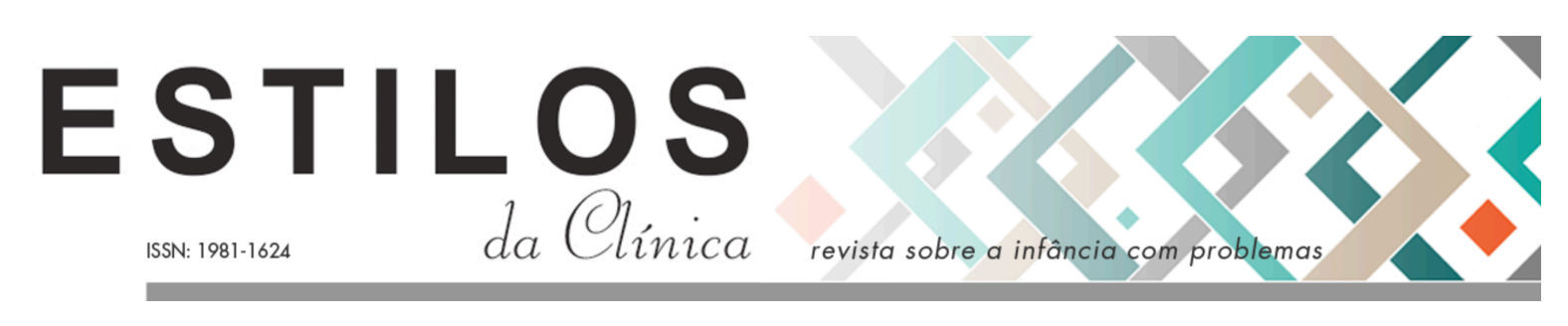

DOI: https://doi.org/10.11606/issn.1981-1624.v26i1p160-179.

\title{
Fundamentos
}

\section{A constituição subjetiva no grafo do desejo de Lacan}

\author{
Renato Jesus Aparecido de Praga Palma; Marco Antonio Coutinho Jorge
}

Resumo. O presente trabalho objetiva discorrer sobre como a psicanálise considera o processo de constituição do sujeito, tomando como base o grafo do desejo estabelecido por Jacques Lacan no final da década de 50 como modelo que coloca em correlação o processo de constituição subjetiva e os processos encontrados em uma análise. Será realizada uma investigação sobre a subversão da ordem instintual quando se é constituído pelo significante. Para isso, considerou-se necessário abordar o decurso das primeiras relações da criança com o outro, tratando das relações do sujeito mítico da necessidade, do atravessamento da demanda, e do seu mais além, o desejo.

Palavras chave: constituição do sujeito; grafo do desejo; real; simbólico; imaginário.

\section{La constitución del sujeto en el grafo del deseo de Lacan}

Resumen. El presente trabajo tiene como objetivo discutir cómo el psicoanálisis considera el proceso de constitución del sujeto, basado en el grafo del deseo establecido por Jacques Lacan a fines de los años 50, como un modelo que correlaciona el proceso de constitución subjetiva y los procesos encontrados en la clínica psicoanalítica. Se realizará una investigación sobre la subversión del instinto cuando la constitución ocurre a través del significante. Para esto, se consideró necesario abordar el curso de las primeras relaciones del niño con el otro, abordando las relaciones del sujeto mítico de la necesidad, del cruce de la demanda, y del tú más allá, el deseo.

Palabras clave: constitución del sujeto; grafo del deseo; real; simbólico; imaginário.

\section{The subjective constitution in Lacan's graph of desire}

Abstract. The present work aims to discuss how psychoanalysis considers the process of constitution of the subject, based on the graph of desire established by Jacques Lacan at the end of the 50s as the model that puts in correlation the process of subjective constitution and the process found within the psychoanalytic clinic. An investigation will be carried out on the subversion of the instinctive order when the subject is constituted by the signifier. In that way, we consider necessary to approach the course of the child's first relations with the other, considering the relationships of the mythical subject of need, the crossing of demand, and its beyond, the desire.

\footnotetext{
* Psicólogo e psicanalista. Doutorando em Psicanálise pelo Programa de Pós-graduação em Psicanálise do Instituto de Psicologia da Universidade do Estado do Rio de Janeiro, Rio de Janeiro, RJ, Brasil. E-mail: renatoppalma@hotmail.com

** Psiquiatra e psicanalista. Professor associado do Departamento de Psicanálise do Instituto de Psicologia da Universidade do Estado do Rio de Janeiro, Rio de Janeiro, RJ, Brasil. E-mail: macjorge@,macjorge.pro.br
} 
Keywords: constitution of the subject; graph of desire; real; symbolic; imaginary.

\section{La constitution subjective dans le graphe du désir de Lacan}

Résumé. Le présent travail établi une discussion sur la manière dont la psychanalyse considère le processus de constitution du sujet, basé sur le graphe du désir construit par Jacques Lacan à la fin des années 1950 comme modèle qui met en corrélation le processus de constitution du sujet et les processus trouvés dans la clinique psychanalytique. Une recherche sera menée sur la subversion de l'instinct dans la mesure où on est constitué par le signifiant. Dans ce but, il a été jugé nécessaire aborder le cours des premières rapport de l'enfant avec l'autre, en approchant des relations du sujet mythique de la nécessité, de la traverser de la demande, voire l'au-delà, le désir.

Mots-clés: constitution du sujet; graphe du désir; réel; symbolique; imaginaire.

grafo do desejo é um modelo construído por Jacques Lacan no final da década de 50 baseado na geometria não métrica e visa conectar vetores e lugares para condicionar certas relações. Ele representa um sistema de coordenadas lacano-cartesiano, que tem a pretensão de explicar não apenas o processo de constituição subjetiva, como também os processos encontrados dentro de uma análise, como a transferência, as construções em análise e a interpretação.

Em dois seminários sucessivos, As formações do inconsciente (1957-1958/1999) e O desejo e sua interpretação (1958-1959/2016), e no texto dos Escritos "Subversão do sujeito e a dialética do desejo no inconsciente freudiano" (1960/1998), Lacan constrói passo-a-passo esse modelo na tentativa de explicar como a inoculação do significante no campo do vivo subverte a natureza. E a definição de Real, Simbólico e Imaginário, estabelecida por Lacan na conferência de fundação da Sociedade Francesa de Psicanálise em 1953, intitulada $O$ simbólico, o imaginário, o real, se apresenta como base de entendimento do grafo do desejo e perpassa toda a sua definição. Lacan (1953) os define como três tipos de registro distintos para designar três formas de inscrição que fundam o psiquismo, sendo eles os "três registros bem distintos que são, efetivamente, os registros essenciais da realidade humana, e que se chamam simbólico, imaginário e real" (p.12).

Fazendo uma investigação do termo 'registro' nos dicionários franceses, Vicent Clavurier (2010) observa que o termo advém do latim a partir do particípio passado de regerere, tendo o sentido de relato, de inscrição, de gravação. E ao designar Real, Simbólico e Imaginário, Lacan apresenta formas de notação diferenciadas, que possibilitam "fazer registro" de maneiras distintas. R.S.I. advém como referenciação para situar os fenômenos da clínica, representando "um paradigma tão importante para a psicanálise lacaniana quanto as tópicas freudianas" (p.125). Eles são reduzidos a letras (R, S, I), que servem de coordenadas para registrar o trajeto do sujeito em sua constituição, como também marcos para ler e escrever o percurso de uma análise.

O imaginário vem a ser apresentado inicialmente para descrever os ciclos instintuais dos animais; o simbólico, como o campo da fala e da linguagem, que exprime que nenhum elemento tem uma significação em si mesmo, mas deve ser articulado, referido ao sistema simbólico no qual se insere; e o real é apresentado como aquilo que não tem nenhum sentido, que não pode ser nomeado precisamente por ser impossível de ser simbolizado. Ele constitui aquela parte que 
escapa ao compósito simbólico-imaginário que se apresenta como uma realidade dotada de sentido. O real não tem sentido, e pode ser evidenciado, por exemplo, nos automatismos, nos sonhos traumáticos e nas repetições sintomáticas, àquelas em que o sujeito, mesmo não entendendo por que as repete, assim as faz.

Embora essas três dimensões venham a ser retomadas ao longo da obra de Lacan como dimensões que não podem ser separadas umas das outras, por questão didática apresentaremos separadamente esses registros, para que, a partir disso, possamos articular as etapas de construção do grafo do desejo com o processo de fundação subjetiva.

\section{A constituição do sujeito no registro imaginário}

Ao definir o que seria o imaginário, Lacan primeiramente observa que ele não tem nada a ver com a imaginação, mas que estaria ligado à dimensão dual, especular, isto é, à imagem corporal, que nos desenvolvimentos finais do ensino de Lacan, estaria associado à dimensão do sentido (Jorge, 2000, 2010, 2017).

No escrito intitulado $O$ estádio do espelho como formador da função do [eu] ${ }^{1}$ tal como nos é revelada na experiência analítica (1949/1998), Lacan retomou as teorias do anatomista Louis Bolk e dos etólogos Harrisson e Chauvin para salientar que o filhote do homem possui um período curto de vida intrauterina, o que o faz 'nascer prematuramente', marcado por um estado de inacabamento anatômico nos meses neonatais. Seu estado de fetalização é verificado pelos sinais de mal-estar e pela falta de coordenação motora. Imerso em um estado de completa dependência dos outros à sua volta, Lacan observa a força de atração que a imagem do adulto tem para a criança e como essa imagem é tomada por ela como modelo de identificação. Partese, portanto, de uma imagem própria despedaçada (denominada por Lacan de 'corpo espedaçado') e da falta de um saber a priori que responderia às suas necessidades primárias, para uma completa dependência do outro a sua volta e para um prestígio da imagem desse outro, a qual assumirá referência para a construção de sua própria imagem. $\mathrm{O}$ que Lacan vem nos dizer é que a construção da imagem própria (o corpo próprio, em oposição ao corpo espedaçado) só é possível pelo bebê tomar a imagem do outro como modelo. Essa identificação se apresenta como ponto de partida para a construção do eu, de uma imagem coerente, gestáltica e que tenderá a se cristalizar a tal ponto que Lacan falará da força de uma estátua pregnante. (Lacan, 1951/1995).

Vê-se que nesse escrito, Lacan apontou a importância da construção do eu como o primeiro tempo no processo de constituição do sujeito. Segundo ele, a edificação egoica só é possível na relação com o outro, ou seja, é somente a partir da imagem do outro e com o qual a criança se identifica que há a possibilidade de haver um reconhecimento de si mesmo. A primeira experiência imaginário-identificatória proporciona a constituição de uma imago ${ }^{2}$ que não existia anteriormente, visto que antes desse momento só podíamos falar em termos de materialidade fisiológica, neuronal, trocas químicas, dentre outros.

Em 1914, no ensaio sobre Introdução ao Narcisismo, ao discorrer sobre as três fases do desenvolvimento da libido, Freud indicou que o primeiro objeto de investimento da criança

\footnotetext{
${ }^{1}$ Respeitou-se a versão utilizada pela tradução brasileira, cuja indicação afere que [eu] (grafado entre colchetes) se refere ao sujeito do inconsciente, enquanto eu (sem colchetes) alude à instância imaginária moi.

2 O termo 'imago' é conceituado por Laplanche e Pontalis (2004) como uma representação inconsciente de personagens, baseada em uma construção imaginária, que orienta a forma como o sujeito apreende o outro a sua volta e a si mesmo.
} 
seria a sua própria imagem, o eu, imagem construída pelas relações da criança com o outro. Mas conforme as palavras de Elisabeth Roudinesco (2006), o culto de si mesmo não é correlato a uma conquista ou a alguma forma de ganho, mas sim a uma busca desvairada de encobrir o vazio. Como sublinha Bertrand Ogilvie (1991) "tudo começa por uma perda e prossegue, ironicamente, num desenvolvimento que procura tampar por uma fuga para adiante essa falta que é na realidade a sua causa" (p. 118).

Lacan (1949/1998) aferiu que a construção da imagem corporal é o que vai possibilitar alterar esse estado primeiro e culminar em uma experiência de unidade, de uma imagem bem configurada de si mesmo. A experiência de imagem despedaçada do seu próprio corpo é sucedida por um estado de júbilo e de fascinação tanto da sua imagem refletida no espelho, quanto da sua imagem traduzida na fala dos que dizem dela. Assim, o infans, de acordo com Freud (1914/1998), se identifica com seu duplo, sua imagem especular (eu ideal), através da qual mede o seu eu atual.

Para abordar essa questão, Lacan retomou a descrição do Estádio do espelho, tal como é demonstrada por Wallon em seu trabalho As origens do caráter da criança (1971), para falar sobre como o infans é capaz de reconhecer-se diante do espelho e também de interpretar a realidade. O estádio do espelho, que é vivido entre os seis e os dezoito meses, se dá, segundo Wallon, em três tempos: no primeiro, ao se posicionar diante do espelho, a criança não interpreta que aquilo que ela vê seja apenas uma imagem, mas a considera como uma realidade, pois ainda não há a distinção entre ela e o outro. Já no segundo momento, a criança reconhece que o outro do espelho se trata apenas de uma imagem. E, por fim, no terceiro tempo, ela reconhece que a imagem do espelho é a dela própria.

Esse reconhecimento só é possível pelo auxílio do Outro ${ }^{3}$ que sanciona a percepção dessa imagem pela criança. Nessa relação, a criança "se volta para o adulto, como que para invocar o seu assentimento, e depois retorna à imagem; ela parece pedir a quem a carrega, e que representa aqui o grande Outro, que ratifique o valor dessa imagem" (Lacan, 1962-1963/2005, p. 41). Assim, essa experiência não está ligada exclusivamente ao objeto espelho, mas também a um Outro que confirma e que edifica a sua imagem. Esse grande Outro é assumido por um semelhante e adquire o lugar daquele que porta um saber e uma verdade. Ele é quem confere à criança um lugar no mundo simbólico através do fornecimento de uma série de significantes com os quais ela possa se identificar.

É como significante que a imagem entra em jogo em seu diálogo, e é como significante que ela representa alguma coisa. Isso é particularmente evidente pelo fato de que nenhuma delas se sustenta por si mesma. É sempre com relação a uma outra dessas imagens que cada uma delas assume seu valor cristalizante, orientador, que ela penetra o sujeito em questão, a saber, a criança pequena. (Lacan, 1956-1957/1995)

Portanto, essa relação imaginária, formadora do eu e que aparenta à consciência uma ilusão de unidade, só é definida em virtude de uma dimensão simbólica. É apenas por um outro semelhante encarnar um estatuto simbólico, de um Outro que olha para o bebê, que confirma a sua imagem, mas que também o nomeia e lhe atribui diversos adjetivos, que este último o toma como referência e vem a se constituir, adotando para si os significantes do Outro.

\footnotetext{
${ }^{3}$ No seminário O eu na teoria de Freud e na técnica da psicanálise (1954-1955/1985) Lacan formulou o conceito de 'grande Outro' (representado por A maiúsculo, por ser a primeira letra da palavra francesa Autre) para se referir ao campo da linguagem, ao código, ao 'tesouro dos significantes'. É um campo que, apesar de ser assumido por um semelhante, remete ao registro simbólico, a toda estrutura social e cultural circundante. Para Lacan, a distinção entre Outro e outro corresponde à diferença estrutural, inaugurada por seu ensino, entre simbólico e imaginário.
} 
É importante observar que no artigo sobre o estádio do espelho Lacan ainda não diferenciou os pronomes je de moi; dois vocábulos que se traduzem pelo termo eu. Posteriormente, ao sistematizar esses termos, Lacan aferiu que moi faria referência àquela instância imaginária e alienante atribuída ao eu, tal como descrita em 1949, enquanto o pronome je faria alusão ao sujeito do inconsciente e à sua articulação com o registro simbólico, revelando a excentricidade do sujeito diante daquela instância imaginário-identificatória. Mas mesmo ainda não fazendo essa distinção, Lacan já esboçou em $O$ estádio do espelho a diferença entre eu e sujeito, distinção necessária devido às séries de modificações empreendidas pelos psicanalistas pósfreudianos em relação aos conceitos cunhados por Freud.

\section{A constituição do sujeito no registro simbólico}

Se no campo instintual, isto é, nos animais, o imaginário advém como um script, como uma lei ordenada que rege todo o seu comportamento, e que é evidenciado nos comportamentos estereotipados de reprodução, acasalamento, proteção da prole, defesa de território, etc., o imaginário no campo do humano não é um registro completo, sem furos, que instituiria e descreveria todo o comportamento humano. No âmbito do sujeito falante há um cavo no imaginário, uma "hiância congênita que o ser real do homem apresenta em suas relações naturais" (Lacan, 1955/1998, p. 416). Diante da incidência de um cavo estrutural, o campo simbólico sobrevém como um artifício através do qual o sujeito tenta lidar com essa falta real que nunca é tamponada. É nesse lugar simbólico que Lacan situou o campo da linguagem, o espaço que possui um sistema articulado e que é constituído inconscientemente por uma cadeia significante, o campo cuja lógica de funcionamento segue os procedimentos gramaticais da metáfora e da metonímia.

O conceito de significante, tal como anunciado por Lacan, é retirado dos desenvolvimentos do fundador da linguística estrutural, Ferdinand Saussure, quando este, em seu Curso de Linguística Geral (2004), concebeu pela primeira vez a natureza do signo linguístico e com isso deu um passo essencial em relação à filologia. Se esta estuda a linguagem do ponto de vista diacrônico (evolução das línguas através do tempo), a linguística criada por Saussure, ao desvelar a estrutura do signo linguístico em seu comparecimento universal, possibilita o estudo sincrônico de forma inédita nos estudos da linguagem.

Para Saussure (2004), a menor unidade linguística - o signo - é constituída pela relação entre dois termos: o conceito (significado) e a imagem acústica (significante). A imagem acústica envolve a impressão psíquica de um som material sobre o sujeito, ou seja, ela abarca a possibilidade de se representar um som. A evidência de tal impressão é demonstrada, segundo o autor, pela possibilidade de se recitar um poema sem a necessidade de se mover os lábios. Saussure (2004) produziu uma notação sobre o signo linguístico, que é demonstrada no esquema abaixo:

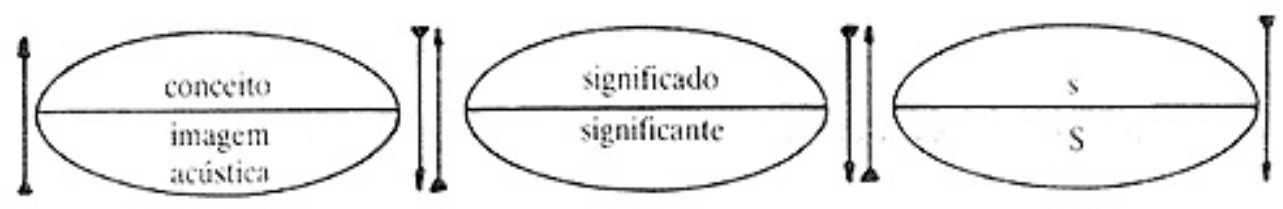

Figura 1. Notação sobre o signo linguístico 
Para o linguista, um significante sempre estaria correlacionado a um significado, o que o fez definir o signo linguístico como uma unidade indissociável, como os dois lados de uma folha de papel, de modo que o significado sempre remeteria ao significante assim como o significante ao significado. $\mathrm{O}$ signo se apresentaria como uma unidade bifacial, possuindo uma relação unívoca entre os seus termos e esse é o sentido da elipse e das setas em seu esquema. E por acreditar em uma relação fechada entre significante e significado, Saussure aceitava como verdadeira a possibilidade de a língua comportar a comunicação sem furo, e, com isso, produzir um consenso linguístico absoluto.

Enquanto o linguista estava trabalhando com o aspecto denotativo da língua, com a colagem entre significante e significado, Lacan se preocupou com o caráter conotativo da língua e com o que se produz no ato da fala. Ele enfatizou a enunciação e a produção subjetiva, isto é, aquilo que está para além das normas do enunciado e das significações dadas de antemão. Para o psicanalista, a linguagem não comporta exclusivamente a dimensão da comunicação nem do entendimento; ela abarca igualmente os equívocos, as falhas, os tropeços e os mal-entendidos. Como sublinha Noga Wine (1992), "o falante faz vigorar, no ato da fala, uma outra ordem, que não é a da comunicação; passa algo a mais, que não é o conteúdo designado pelo signo. Essa é a ordem que está para além da dimensão imaginária da comunicação" (p. 67).

Ao questionar a colagem entre significante e significado, Lacan (1957/1998) inverteu a relação s/S (significado sobre significante) e argumentou que é o significante que tem primazia. O significante não atende à função de representar o significado, mas ele precede a produção deste último e o determina. Ao fornecer como exemplo o par noite/dia e homem/mulher, Lacan salientou que um significante, seja ele um fonema ou uma palavra, não tem sentido em si mesmo, mas que sua significação só advém por uma relação diferencial desse elemento com outro: "a estrutura do significante está em ele ser articulado" (Lacan, 1957/1998, p. 504). O significante, portanto, nada significa, ele é pura marca, ele é a primeira coisa que acede ao infans e incide como um traço, como uma escrita simbólica no corpo orgânico. Ele é uma máquina sonora sem sentido algum, que quando inoculado no campo do ser permite subverter a natureza.

Para descrever a relação da cadeia significante com a cadeia dos significados, Lacan construiu um esquema considerado como a célula elementar da relação do ser vivente com o campo da linguagem. Esse esquema, evidenciado no seminário As formações do inconsciente (1957-1958/1999), também é o suporte para a construção e o entendimento do grafo do desejo.

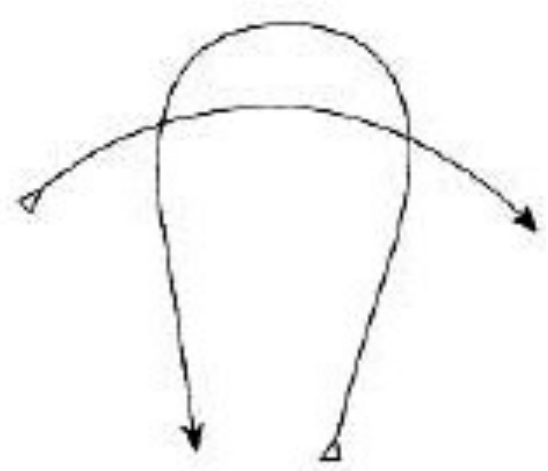


Como é observado, há dois vetores que se entrecruzam nesse grafo: a linha que parte da esquerda para a direita se refere ao caminho do dizer, ao caráter linear dos significantes se encadearem, ou seja, à possibilidade de eles formarem cadeia pelos efeitos de metáfora e de metonímia. Esse eixo expressa o caráter diacrônico da frase, o que denota que um termo deve vir depois do outro. Já o segundo vetor, que vai da direita para a esquerda, se refere à linha dos significados, aos conceitos já estabelecidos socialmente. Lacan salientou que inicialmente há um contínuo deslocamento da cadeia significante sobre a cadeia dos significados, e que não há nenhum laço entre eles, ou seja, se por um lado há apenas significantes que, por meio de uma lógica combinatória, selecionam quais serão os significantes ulteriores, por outro, há um conjunto de valores consensuados.

Mas a partir do exemplo do nó de estofamento, que, em um tipo de sofá classicamente chamado de captonné, permite conter o deslizamento entre a espuma e o tecido que a recobre, Lacan buscou ilustrar o advento da significação. Verifica-se que a produção da significação só é estabelecida no momento em que significante e significado se atam, o que é denominado ponto de estofo ou de basta (point de capiton). A partir de uma pontuação no caminho do dizer, a frase para e retroativamente dá-se um sentido a ela. Essa processo é observado no esquema acima, mas é mais bem demonstrado na figura 4, quando o autor mostrou que a significação se dá no sentido de $\mathrm{A}$ (segundo ponto de interceptação entre os dois vetores) a $\mathrm{s}(\mathrm{A})$ (primeiro ponto de cruzamento). De acordo com Angela Bernardes (1999), esse esquema reverso no caminho da significação sugere que é a partir de A, do tesouro dos significantes, que um significante pode ganhar um significado - $\mathrm{s}(\mathrm{A})$. É o grande Outro que submete todos os significantes, até então disjuntos, ao código, marcando as suas relações mútuas segundo essa referência simbólica.

A noção freudiana de a posteriori ou a posterioridade (em alemão, Nachträglich e Nachträglichkeit), resgatada por Lacan em sua leitura de Freud e até então não apreendida em sua qualidade conceitual pelos psicanalistas, permitiu a Lacan conceber um dos aspectos essenciais da teoria do significante. Ao anunciar o mecanismo de retroação, Lacan (1960/1998) demonstrou que quando o ser vivente $(\Delta)$, entidade mítica pré-simbólica (também chamada por Lacan de proto-sujeito), é interpelado pela bateria significante $\left(\mathrm{S}_{\rightarrow} \rightarrow \mathrm{S}^{\prime}\right)$, há como resultado a produção de um sujeito do significante (\$), como é evidenciado na imagem abaixo. A inoculação de uma série de significantes no campo do vivo, além de toda interpretação que o Outro emite sobre um mero grito ou balbucio do recém-nascido, alude à estrutura simbólica que o antecede e que o constitui como sujeito, como servo da linguagem. A ambiguidade do termo sujeito é aqui reveladora dos dois aspectos do termo: a potência enunciadora se amalgama com o assujeitamento à linguagem. 


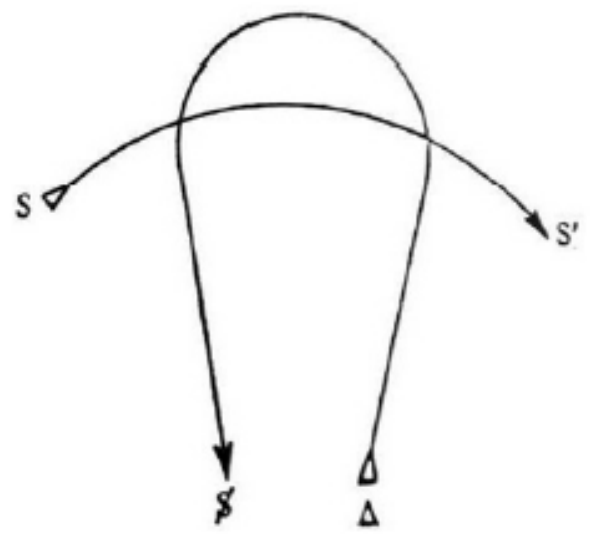

Figura 3. Primeira etapa do grafo

Na famosa querela do Congresso de Bonneval em 1966 que o opôs à Laplanche e Leclaire, para os quais o inconsciente é a condição para a linguagem, Lacan (1970/2003) nos lembra que "a linguagem é a condição para o inconsciente" (p. 409), o que permite aludir que a estrutura inconsciente advenha no processo que introduz o infans ao universo simbólico. É a inscrição do significante no ser vivente que o faz ser marcado, dividido e subvertido pela linguagem, e, por isso, assujeitado ao inconsciente.

Mas sujeitar-se à linguagem traz como consequência tornar-se um sujeito apagado, sem significado e não dotado de funções cognoscentes. Significa apenas ser representado por palavras, inserido à lei significante e representado de um significante a outro. Para Lacan (1964 [1960]/1998), o lugar do significante se organiza pelo fato de um significante representar um sujeito para outro significante. E a divisão do sujeito reside aí, ele é dividido pelos significantes, é como se o processo de um significante se vincular a outro deixasse o sujeito obscurecido, à parte de todo o processo, fazendo-o emergir apenas nas brechas da fala, como um lapso, o que faria com que o eu do sujeito se deparasse com o que já se produziu, ou seja, com a manifestação das formações do inconsciente.

Dessa forma, o sujeito seria uma irrupção transitória e se manifestaria como um furo no discurso, trazendo algo extrínseco e estranho ao discurso racional; sua relação com o significante se ilustra através de "uma enunciação com que o ser estremece pela vacilação que lhe retorna de seu próprio enunciado" (Lacan, 1960/1998, p.816). Mas é importante observar que logo após essa manifestação transitória o sujeito desaparece novamente e se submerge por detrás de um ou de alguns significantes $\left(\mathrm{S}_{1}\right)$ com os quais ele se identifica. $\mathrm{S}_{1}$ é um conjunto de significantes que fornece uma referência simbólica para o sujeito e o singulariza; é, por exemplo, o nome próprio, o gênero, etc. No entanto, o princípio que rege a lei significante nos lembra que nenhum significante possui um significado por si mesmo: um nome próprio - $\left(\mathrm{S}_{1}\right)$ -, por exemplo, só tem sentido em sua referência ao conjunto de nomes próprios - $\left(\mathrm{S}_{2}\right)$.

E por não ter um significado que lhe dê um estatuto de ser, o sujeito demanda, dirige-se ao Outro (A) em busca de sentido, na procura de um significante derradeiro que o represente - é o que é anunciado logo abaixo, na segunda etapa de construção do grafo do desejo. Mas essa tentativa de tamponar a falta de significado não se encerra, justamente porque um significante não possui em si potência representativa. Na notação S/s (significante sobre significado), o traço, que para Saussure era de interface, para Lacan é de resistência à significação, o que faz do significado algo inalcançável pelo significante. 


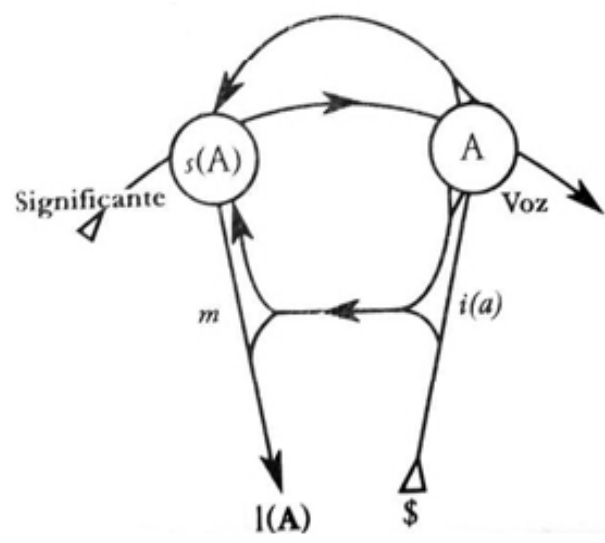

Figura 4. Segunda etapa do grafo

A - grande Outro, tesouro dos significantes

$\mathrm{s}(\mathrm{A})$ - significado do Outro

I (A) - Ideal do Outro, Ideal de Eu

$m-$ eu (registro imaginário)

$i(a)$ - outro especular

Ser constituído pelo significante e, por conseguinte, fazer uso desse artifício simbólico é não apenas transformar o que era do campo do vivo em sujeito da linguagem, como também alterar o que era do plano da necessidade em desejo. A atribuição sígnica que é expressa na necessidade é perdida, isto é, o que advém no significado não traduz necessariamente a falta expressa. Isso ocorre pelo fato de que, no campo do humano, incidiu uma falta insaturável que jamais é passível de ser tamponada ou significada, mas que é apenas contornada por significantes em uma tentativa de apreendê-la. Nesse campo, a falta é colocada em palavras, é articulada segundo a regra linguageira do grande Outro, ou seja, pelo duplo jogo de combinação e de substituição significante. Tudo se passa agora pelo viés da demanda, pelo endereçamento ao Outro e por sua articulação segundo os princípios operativos dessa instância simbólica.

Portanto, a dinâmica da demanda segue o princípio operativo da busca de significação, de atamento entre significante e significado, sendo este significado - $\mathrm{s}(\mathrm{A})$ - produzido a partir do tesouro dos significantes - A. O que está fora ou para-além do ponto de basta, da produção de sentido, é denominado por Lacan como voz, como aquilo que não está inserido no sistema de significação, sendo desprovido de sentido; a voz é tudo o que, como significante, não converge para o efeito de significação.

Nessa segunda etapa do grafo, Lacan inseriu a questão da identificação a dois ideais baseando-se na falta de significação do sujeito. O desfecho encontrado à carência de significação é a identificação ao eu ideal, que culmina na fixação a uma imagem - $i(a)$-, e ao ideal simbólico, do Outro - I(A). O primeiro diz respeito à captura imaginária, à construção da imagem de si próprio a partir da imagem do outro. Essa relação imaginário-identificatória é meramente especular e apresenta a fórmula de como eu me vejo na relação com os outros. É o que se escreve na notação $m-i(a)$, ou seja, eu - eu ideal, sendo este último nada menos que o espelho, ou o outro especular, aquele a partir do qual o sujeito se vê e se avalia. Por outro lado, o ideal simbólico diz respeito a uma identificação às insígnias do grande Outro, pois, como afirma Eny Lima Iglesias (1996), "o Outro foi investido de onipotência, do poder que recebe por encarnar o lugar da palavra e ser testemunho da verdade" (sem página). Diante de sua falta de significado, de seu desaparecimento, a via buscada pelo sujeito é a constituição de um 'um' 
a partir de uma imagem tomada do Outro - i(a) -, que funciona como um ideal - I(A) - para esse sujeito, constituindo o seu eu - moi.

\section{O Édipo e a constituição da fantasia fundamental}

Somos derivados da linguagem e somos convocados a expressar, a balbuciar algo que venha em nosso socorro e nos livre do desamparo. E para que possamos nos constituir no campo da linguagem, somos tomados em um primeiro momento por um outro semelhante, que incorpora para nós esse campo ao qual ele também está assujeitado (Sirelli, 2010). Necessitamos nos alienar ao dito do Outro para que, assim, possamos nos constituir no campo da palavra, o que Lacan resume ao enunciar que "a alienação é própria do sujeito" (1964 [1960]/1998, p. 854).

Lacan (1957-1958/1999) salientou que é a mãe - ou quem assume esse lugar - que irá encarnar o estatuto de um Outro para a criança, um Outro que se ocupa em lhe conferir um nome e um lugar no mundo simbólico. Trata-se de um Outro onipotente, sem lei, revelando o que Lacan chamou de 'lei da mãe', visto que "essa lei está, toda ela, no sujeito [mãe] que a sustenta, isto é, no bem-querer ou malquerer da mãe" (p.195). A criança advém como um assujeito, "assujeitada aos caprichos daquele de quem depende" (p. 195), sendo inserida imaginariamente ao desejo do Outro materno pela via significante.

Essa operação é vivenciada pela criança na entrada do complexo de Édipo, que se dá em três tempos lógicos.

No primeiro tempo, a criança busca se igualar imaginariamente a esse lugar que a mãe fornece a ela; em outras palavras, ela busca ser o objeto do desejo da mãe, objeto designado falo. Nesse momento, a criança não depende "da simples apetência das atenções, do contato ou da presença da mãe, mas da apetência do seu desejo" (Lacan, 1957-1958/1999, p.188). A passagem para o segundo tempo se dá pela constatação da criança de que a mãe também se dirige a um terceiro - geralmente o pai ${ }^{4}$-, o que indica que o desejo da mãe está para além da criança. Nessa dialética, a criança supõe ao pai ser o falo da mãe, e não mais ela, o que faz culminar em uma rivalidade imaginária com o pai. Seria pelo desejo da mãe ser disposto como um $x$, como um enigma, que se processaria uma busca imaginária da criança na tentativa de descobrir qual seria o objeto que satisfaria o Outro materno, em uma tentativa de sê-lo.

No entanto, a mãe também está assujeitada ao campo da linguagem, ao dito do Outro. E é por ela se remeter a um significante, que é encarnado pela figura do pai ou por qualquer outra que cumpra metaforicamente o lugar de lei para ela, que a instância paterna se eleva a um estatuto simbólico, fazendo do Nome-do-Pai um operador que vem desbancar o reinado absoluto do Outro materno. É necessário ressaltar que é a mãe que irá se remeter à lei, ou seja, é o discurso da mãe que dá a palavra ao pai como o representante da lei. Isso indica que a lei não é mais dela, mas de um Outro, que agora é representado pelo pai, ao qual ela também se subordina.

O pai, portanto, que anteriormente era constatado pela criança como o falo da mãe, é elevado, nesse momento, a um pai que supostamente tem o falo. Mãe e criança passam a depender de um objeto que o pai tem ou não tem. Em decorrência disso - já no terceiro tempo - a criança constata que se pode ter ou não ter o falo, e quem o tem pode perdê-lo. O falo é assim elevado à condição simbólica, passando a existir independente de um personagem, fazendo de todos

${ }^{4}$ Terceiro que estabelece uma triangulação e que fisga o desejo da mãe para além da criança, deslocando-a do lugar de objeto da completude imaginária daquela. 
castrados, inclusive o pai - incidência da castração como operação simbólica. Com isso, o falo, enquanto objeto metonímico, passa a circular na cadeia significante, resultando não mais em uma identificação imaginária, mas sim na busca de se identificar ao significante que remeta a ele.

Observa-se aí que a incidência da lei do pai vem abalar a criança em sua posição de assujeito. É na medida em que o pai advém como proibidor que o sujeito é tirado da sua posição de objeto de desejo do Outro materno, objeto esse que adquire nesse momento um estatuto simbólico, como o significante da falta, ou, melhor dizendo, como o significante fálico. Ao ser desalojado da sua posição, o sujeito demanda ao Outro, àquele figurado enquanto código de referência, uma resposta sobre o seu desejo e sobre o que supostamente lhe falta. Mas do lugar de onde ele espera um oráculo, retorna-lhe a pergunta "Che vuoi?" - Que quer você? (Lacan, 1960/1998, p. 829).

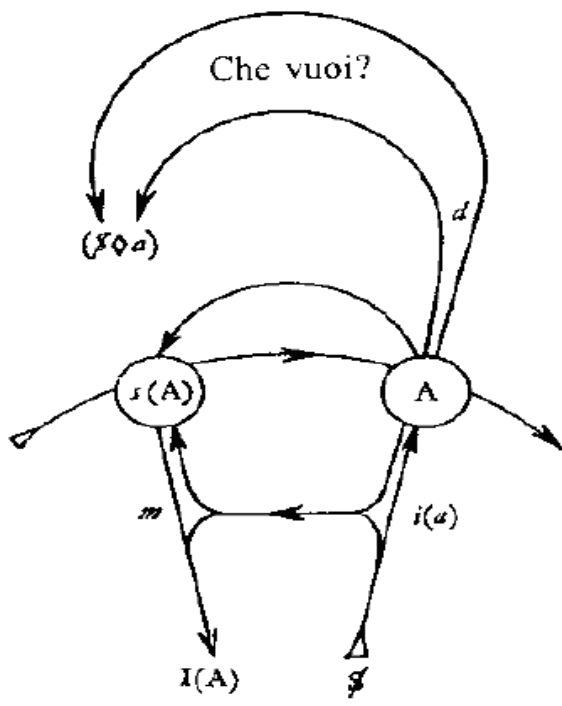

Figura 5. Terceira etapa do grafo

$d=$ desejo

Che vuoi $?=$ Que queres?

$\$<a=$ fórmula da fantasia

Na demanda dirigida ao Outro, o sujeito se depara com o vazio, com a não resposta do Outro, o que indica que ele também é faltoso ${ }^{5}$ e que, por isso, não preencherá o vazio criado pela pergunta. Não há verdade alguma a ser encontrada frente à falta do objeto, é ao que Lacan (1960/1998) veio se referir ao afirmar que não há Outro do Outro, nem metalinguagem, visto que nada vem em suplência à incompletude do Outro, este é pura alteridade. A falta no Outro permite que o sujeito se constitua, advindo como falta-a-ser, como um sujeito que não irá obter no Outro uma resposta, nem para o que ele é nem para o seu desejo, sendo assim barrado em seu gozo e em sua significação. Observa-se, assim, no âmago do Outro e, por conseguinte,

\footnotetext{
${ }^{5}$ Se num primeiro momento Lacan define o Outro como o lugar do código, como o detentor do saber, como aquele que preenche o vazio do simbólico, ele sublinha posteriormente que também há uma falha, uma hiância no Outro, assinalando um para além do significante (Lacan, 1957-1958/1999).
} 
também do sujeito, a presença de uma falta, de um vazio, que aponta para um resto sem significação e que possibilita inaugurar o movimento desejante.

Diante do enigmático desejo do Outro, de sua falta irremediável, o sujeito constrói uma costura significante $-\$<a$ - denominada fantasia fundamental, que se constitui como um saber inconsciente em que o sujeito busca responder a questão sobre o seu ser, sobre quem ele é e sobre qual seria o objeto que satisfaria o seu desejo, tentando atribuir um rosto a esse objeto, e, com isso, tamponar a falta inerente a ele. Através de uma articulação simbólico-imaginária, isto é, de palavras e imagens, a fantasia fundamental constitui a realidade psíquica que tampona o real (sem sentido) da falta de objeto e permite ao sujeito se fixar como desejante. (Lacan, 1960-1961/1992). Ela passa a significar uma espécie de prisão domiciliar na qual o sujeito estabiliza, através do princípio do prazer, sua relação com o objeto do desejo (Jorge, 2010).

No seminário A Angústia (1962-1963/2005), Lacan dedicou especial atenção à conceituação desse objeto. Ele o definiu pela letra $a$, visando exauri-lo de qualquer tentativa de objetivação, e nos indicou que esse objeto, o objeto $a$, funciona como a causa do desejo do sujeito. Como aferimos anteriormente, há um momento na relação mãe/criança em que Outro materno desvia o olhar da criança e se dirige a um terceiro, o que denota que ela, a mãe, também é castrada e fisgada pelo desejo. Nessa perspectiva, o desejo do Outro causa o desejo da criança, um desejo de saber sobre qual é o objeto que captura o desejo do Outro materno. Assim, o objeto $a$ se presentifica, segundo Bruce Fink (1998), como o resto produzido quando a unidade hipotética mãe/criança se rompe, rompimento que é devido à própria natureza do desejo. À vista disso, o sujeito visa ignorar a sua divisão e sustenta uma ilusão de completude ao apegar-se ao objeto $a$.

No seminário R.S.I. (1974-1975/s.d.), Lacan argumentou que o objeto a participa dos três registros, possuindo uma vertente real, uma simbólica e outra imaginária. A vertente real faz alusão à perda e à castração. Já os planos simbólico e imaginário do objeto $a$ são aqueles que permitem articulá-lo à cadeia significante, fornecendo-o um rosto na tentativa de reencontrar o objeto perdido. São essas duas últimas vertentes que sustentam o objeto $a$ na fantasia.

A perda do objeto cria um funcionamento em torno do vazio, e a tentativa de preencher esse cavo se dá pela eleição dos mais variados objetos na cadeia significante, os quais adquirem aparências imaginárias do objeto faltoso - i(a). Lacan (1962-1963/2005) argumentou que a imagem, em sua forma $i(a)$, não tem resto, não permite ver o que se perde da divisão do campo do Outro. Ela é marcada pela boa forma e pela aparência gestáltica que supostamente encobriria a vertente real do objeto.

A fantasia participa então da ordem imaginária e adquire a sua função através da sua articulação com o registro simbólico. Ela é construída pela junção e pela disjunção $(<>)$ do sujeito a vários objetos que causam o seu desejo (a), buscando fornecer uma roupagem imaginária a esses objetos e, assim, se defender do caráter real do desejo do Outro. Ela é construída como tentativa de responder ou então de sanar a hiância aberta pelo Che vuoi?.

Logo, o que é evidenciado na fórmula $\$<>a$ é que a fantasia se propõe articular sujeito e objeto, isto é, achar um objeto que complemente o sujeito castrado. E é em referência a isso que Jorge (2010) afirma que a fantasia sempre é "fantasia de completude" (p. 83). Se o desejo do Outro afere que há uma falta radical, a fantasia busca circunscrevê-la e nomeá-la com a finalidade de completar. A fantasia é o suporte do desejo - enuncia Lacan inúmeras vezes e de diferentes formas -, ela indica para onde o desejo deve se direcionar e com qual objeto o sujeito deve se ligar. Ela se defende do desejo em seu caráter real, não significável, e que alude à castração, e constitui agora um desejo contextualizado por sua tela fantasmática, um desejo que 
agora tem, ilusoriamente, objetos com os quais se ligar. De acordo com Žižek (1992), o desejo estruturado na fantasia surge como "uma defesa contra o desejo do Outro, contra esse desejo 'puro' e transfantasístico" (p. 116), modo pelo qual o sujeito faz face ao caráter real da pulsão, resguardando-se contra o desamparo.

O tecido fantasístico faz borda em torno do vazio, de forma que o sujeito se vê circundado por uma infinidade de objetos que se deslocam metonimicamente pela cadeia. Mas todos os objetos de interesse para o sujeito, os quais adquirem um atrativo fálico, remetem ao furo, à falta inerente a todos eles, o que denota a ex-sistência de um objeto de satisfação total ao registro simbólico, e a parcialidade da pulsão, que jamais totaliza a sua satisfação. Desse modo, alienarse no Outro é a forma de recobrir-se pelo sentido e, com isso, ocultar o fato de que o objeto de gozo, de satisfação plena, está perdido, é fazer encobrir a castração.

Em suma, o que Lacan propõe em sua terceira etapa do grafo é a saída tanto do circuito da demanda quanto dos ideais identificatórios apresentados no grafo 2 (figura 4). Essa saída se dá pela via do desejo, sendo esta a única possibilidade de o sujeito avançar para o segundo andar do grafo.

\section{A inclusão do real no grafo do desejo em sua versão final}

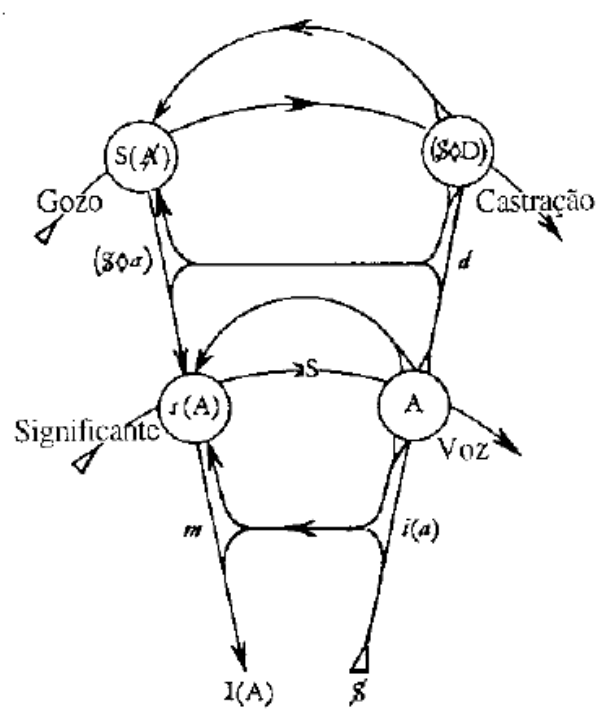

Figura 6. Grafo completo

$\mathrm{S}(\mathrm{A})$ - Significante da falta no Outro

$\$<D$ - Fórmula da pulsão

Lacan observa que o desejo está intrinsecamente vinculado à demanda, uma vez que está articulado às marcas deixadas pela demanda do Outro. Em $A$ direção do tratamento, Lacan (1958/1998) formula a enigmática frase de que o desejo está, ao mesmo tempo, aquém e além da demanda. Aquém pelo fato de a demanda ultrapassar as satisfações que invoca, pois ela se articula em termos simbólicos e se apresenta como demanda de amor. E o desejo, na medida em que revela a pura condição absoluta da urgência, recupera o que se perdera da necessidade 
na demanda, estando aquém desta. Ele toma da necessidade o caráter de urgência, de força impelente, traduzindo em movimentos pulsionais o deslocamento metonímico do significante. Por outro lado, por mais que ele esteja submetido ao filtro da linguagem, o desejo se apresenta como um circuito insistente, indo além de toda demanda articulada em termos simbólicos, sendo um puro fluxo significante. Para Lacan (1959-1960/1991), "o desejo nada mais é do que a metonímia do discurso da demanda. É a mudança como tal” (p. 344). A demanda nunca agarra, nunca captura o que é da ordem do desejo, uma vez que ele sempre está mais além, em outro lugar. Por mais que o desejo se articule à demanda, ele se destaca dela ao restabelecer um segundo desvio.

Uma vez que a necessidade já tenha passado pelo filtro da demanda no plano da incondicionalidade, é apenas a título de uma segunda negação, digamos assim, que reencontraremos, mais além, a margem do que se perdeu nessa demanda. O que encontramos nesse mais além é, precisamente, o caráter de condição absoluta que se apresenta no desejo como tal. (Lacan, 1957-1958/1999, p. 382).

A inserção do desejo no grafo 3 (figura 5), como um mais além das demandas particulares do Outro, abre espaço para um nível que vai muito além do caráter denotativo da língua e dos seus efeitos de significação. O que Lacan propõe na versão final do grafo é que o sujeito não é determinado apenas pelo compósito simbólico-imaginário, mas que no lugar do Outro também subjaz uma falta. Se o andar de baixo do grafo denota que a mensagem se fecha por uma retroação a partir do tesouro dos significantes, o andar de cima evidencia que a cadeia fecha sua mensagem em um significante que especifica que falta um significante no Outro que o completaria - $\mathrm{S}(\mathbb{A})$. $\mathrm{O}$ andar de cima do grafo denuncia um 'além' no circuito simbólico inconsciente, demonstrando que o sujeito também é determinado por algo que faz furo ao enodamento simbólico-imaginário, sendo este o real, representado pela pulsão de morte.

Se a primeira parte do grafo depreende o inconsciente como um saber, como um discurso do Outro que desvela a verdade do sujeito, a pulsão de morte revela um estranho que transborda o reconhecimento. Lacan aproxima a pulsão de morte do irrepresentável, do inabarcável pela cadeia significante. No seminário $O$ eu na teoria de Freud e na técnica da psicanálise (19541955/1985) ela foi associada à máquina, àquilo que podemos designar como o somático intrínseco às pulsões, que caminha só e que quebra a homeostase do princípio de prazer.

Retornando à obra freudiana, a teoria da pulsão veio reorganizar a ideia neurológica anterior a respeito da incidência de estímulos internos do corpo. Apesar de também ser qualificada como uma exigência de trabalho imposta ao psíquico, sua definição ultrapassou o fator motor que ela representa. Ela foi qualificada como um excesso de energia dispersa que advém de maneira constante, mas que só é evacuada quando conectada às zonas erógenas do corpo. Seria em torno dessas localidades que a pulsão se fixa, o que faz com que a sua força impulsiva parta dessas regiões em busca de satisfação.

Se Freud (1905/1998) afirma que a fonte da pulsão é um processo excitatório somático que nasce em um órgão e que tem como alvo a eliminação desse estímulo, Lacan (1964/2008) complementa que é somente no contato com um terceiro, geralmente a mãe ou quem desempenha essa função, que há a possibilidade de se introduzir no corpo zonas de investimento pulsional. Devido ao estado de inacabamento anatômico do recém-nascido e de sua consequente dependência de um terceiro, há a incidência de uma série de demandas simbólicas em algumas regiões do corpo, como a boca, o ânus, os genitais, dentre outras, que remetem aos primeiros cuidados maternos com o bebê. É pela importância que o discurso do Outro fornece a essas 
regiões do corpo que a pulsão aí se fixa. Para o autor, a pulsão está intimamente ligada à demanda (ao Outro e do Outro), fazendo de $\$<>$ D a fórmula da pulsão.

Trata-se aqui de um importante discernimento trazido por Lacan quanto à teoria das pulsões e às chamadas fases da libido. Estas não devem ser consideradas como constituídas biologicamente, mas, ao contrário, se estruturam por meio da incidência da linguagem sobre determinadas regiões do corpo destinadas por natureza às trocas com o Outro: as pulsões constituem "o eco no corpo do fato de que há um dizer" (Lacan, 1975-1976/2007, p.18). A boca não é uma zona erógena enquanto tal, mas o que erogeniza essa região do corpo é a incidência maciça da demanda do Outro - ou seja, da linguagem - sobre esse orifício corporal nas primeiras etapas da vida do bebê (Jorge, 2000, p.50). E, assim por diante, as sucessivas fases da libido manifestam claramente que a demanda do Outro se dirige agora para outros orifícios corporais: o ânus e o ureter, na necessária aquisição do controle esfincteriano que dão a partida para os processos educativos ligados à higiene e à repugnância; os órgãos genitais, quando a atividade masturbatória concentra as repetidas demandas derivadas da atividade repressiva do Outro. Lacan resume a questão ao dizer em suas Conferências norte-americanas que "as assim chamadas fases oral, anal e mesmo urinária estão misturadas de forma demasiado profunda com a aquisição da linguagem". (Lacan, 1976, p.14)

O corpo orgânico se apresenta, portanto, como uma superfície propícia à escrita, tornandose sede das primeiras marcas e dos primeiros investimentos pulsionais. A incidência da linguagem subverte o corpo orgânico em um corpo simbólico, um corpo que, ao se comunicar com o Outro, perde objetos nessa relação (o seio, as fezes, o olhar da mãe que se desvia da criança), fazendo dos orifícios comunicativos zonas erógenas que buscarão reencontrar tais objetos para obter uma satisfação perdida. Lacan (1964/2008) veio falar do sujeito acéfalo da pulsão (p.171) para remeter a essa vertente que clama por satisfação e que produz um sujeito na repetição da busca do objeto perdido.

No seminário O eu na teoria de Freud e na técnica da psicanálise (1954-1955/1985) e em O seminário sobre "a carta roubada" (1956/1998) Lacan iniciou uma investigação sobre qual seria o motor que impulsionaria a repetição, questão muito visualizada na clínica e essencial para elucidarmos com maior clareza os dois andares do grafo do desejo. Neles, o autor descreveu a repetição como simbólica, como uma insistência de elementos significantes que dão nome ao retorno do recalcado. Lacan partiu da descoberta freudiana do jogo infantil do Fort-da para sublinhar a determinação simbólica no psiquismo. A noção de Fort-da originouse da observação de Freud ao ver seu neto brincar de uma maneira peculiar com um carretel amarrado em um cordão. A criança jogava o carretel para longe de tal modo que ele desaparecia aos olhos dela, e, nesse momento, ela exclamava um sonoro ó-ó-ó-ó, que constituía um rudimento da palavra Fort (longe). Logo em seguida ela o trazia de volta, pronunciando um da (aqui). Freud observou que o carretel era um substituto, uma metáfora da mãe e o jogo simbolizava as idas e vindas dela, isto é, a alternância de sua presença e ausência. A criança não podia controlar as saídas da mãe, mas ela tinha a capacidade de simbolizar essa experiência de modo que a tensão decorrente da perda era substituída e aliviada de outro modo, pela atuação simbólica. Esse registro emergia como uma tentativa de lidar com o real do acaso, o simbólico impulsionava a lei da repetição como uma constante tentativa de inscrever esse 'estranho' na linguagem.

Para exemplificar a lei da repetição no psiquismo e sua relação com esse 'estranho', Lacan (1956/1998) partiu do jogo do par ou ímpar para mostrar que, a partir de uma imprevisibilidade, de uma contingência da realidade, pode-se estabelecer um determinado tipo de organização, 
uma lei simbólica particular que rege o psiquismo e a qual todos os mecanismos de atuação e de repetição devem obedecer.

Seguindo a lógica desse jogo, Lacan utilizou os símbolos (+) e (-) para representar a alternância dos resultados provenientes de cada partida. Pela contingência do resultado de cada jogo, pode-se obter, por exemplo, a seguinte sequência de elementos (+++---+-++). Lacan agrupou cada um desses elementos a partir de uma lógica construída por ele, de modo que o grupo constituído por três sequências semelhantes (+++ ou ---) seria representado pelo número 1 , já o conjunto constituído por dois elementos iguais e um diferente (++- ou --+ ou -++ ou +-) seria designado pelo número 2 , e o número 3 representaria o grupo onde houvesse a alternância de elementos (-+- ou +-+). A partir disso, obteríamos o seguinte resultado:

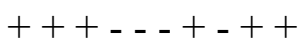

\section{2}

Partindo dessa análise, percebemos que depois de uma sequência 2 podem surgir conjuntos de número 1, 2 ou 3. No entanto, depois de uma sequência 1 é possível aparecer apenas encadeamentos 1 ou 2, e não 3. O mesmo vale para a sequência 3, a partir da qual só é possível aparecer sequências de número 2 ou 3 . O objetivo dessa demonstração baseia-se na ideia de que, quando agrupamos uma sequência de respostas aleatórias a partir de uma determinada classificação, os resultados seguintes passam a seguir essa lei de arranjo, definindo os resultados possíveis e impossíveis. Em outras palavras, apesar de a resposta de cada partida ser totalmente imprevisível, pode-se obter uma previsibilidade dos resultados posteriores se todos seguirem a mesma lógica.

Lacan buscou mostrar através desse exemplo que a partir da imprevisibilidade do real criase um enquadramento simbólico específico que rege o percurso repetitivo e que constitui a memória, a lei e, consequentemente, a subjetividade. Memória e repetição surgem em harmonia, uma vez que o simbólico constitui tanto a memória, enquanto saber inconsciente, quanto a lei da repetição, como insistência desse saber produzido na fantasia. Desse modo, a repetição apresentada no período do seminário sobre a carta roubada sob o nome de automatismo de repetição (wiederholungszwang) seria governada e determinada segundo as leis do Outro simbólico. O autômato de repetição é consequência direta dessa memória absorvida dentro das leis do simbólico e que passa a reger a formação da cadeia significante com autonomia.

Se até meados da década de 1950, Lacan associou a repetição ao inconsciente, à ideia de que "não há outra ligação, a não ser a dessa determinação simbólica" (Lacan,1956/1998, p.56), oito anos depois ele veio relacioná-la à pulsão (de morte). Se o automatismo de repetição remetia apenas à insistência de elementos simbólicos, em Os quatro conceitos fundamentais da psicanálise (1964/1985) Lacan considerou que nem tudo é representação, o que o fez questionar qual seria o encontro primeiro que estaria por detrás da fantasia. Nesse seminário, ao examinar o jogo do Fort-da, o autor salientou que a repetição não se apresenta como repetição de uma necessidade, como um pedido de retorno da mãe, mas como "aquilo que, essencialmente, não está lá enquanto representado" (p. 67), referindo que o que movimenta a repetição é um encontro com o real.

Nesse período, Lacan trouxe outro determinante para a constituição da repetição - a pulsão de morte - e utilizou como referência o sonho traumático para pensar a repetição nesse seminário. Aí, ela adquiriu outra significação ao se apresentar como um constante encontro com 
o que é da ordem da falta, do inassimilável, evidenciando um campo para além do princípio de prazer.

Diante disso, se no Seminário 2 o Outro era apresentado como uma instância simbólica que, em si, respondia ao movimento repetitivo, agora ele se mostra como um campo faltoso por ser repetidamente atravessado pelo trauma da pulsão, ou seja, há uma insistência do trauma que transpassa e, ao mesmo tempo, constitui o sistema representativo. $\mathrm{O}$ autor sustentou o descentramento do sujeito, o seu não reconhecimento pelos registros imaginário e simbólico, uma vez que sempre há um ponto de falha que ultrapassa o reconhecimento pela imagem e pelos recursos simbólicos oferecidos pelo Outro.

E é justamente na parte superior direita do grafo, como representante do lugar que, no andar debaixo, é ocupado pelo tesouro dos significantes, que Lacan localiza a pulsão $-\$<>$ D. Como a pulsão está diretamente interligada ao corpo, será aí, no corpo, que o sujeito irá se localizar quando um órgão passa a emitir uma mensagem. Esta mensagem se apresenta como repetição, em que um órgão se comparece como válvula de gozo e independe da fala do sujeito e da produção de sentido, em consequência do esvaecimento da demanda.

A compulsão à repetição rumo à satisfação perdida independe do saber do Outro. Com isso, há uma dimensão prévia, ausente de sentido, não apreensível pela linguagem, e que, por isso, não é passível de significação. O plano do gozo está referido à Coisa, à das Ding, e consequentemente à castração, tornando o campo do Outro perfurado e incompleto. $\mathrm{O}$ único significante que poderia fazer menção à inconsistência da ordem simbólica quando ela é atravessada por uma incursão de gozo seria o significante da falta no Outro - S(A). Žižek (1992) nos fala que seria como proteção à incidência dessa falta no registro simbólico - $S(\mathbb{A})$ - que a fantasia $-\$<a-$ adviria, vindo como possibilidade de constituir uma significação absoluta - s(A). E é a inclusão do nível do gozo, da pulsão de morte, como aquilo que é da ordem do real, que está para além do significante, que confere a forma completa do grafo do desejo.

\section{Considerações finais}

O grafo, em sua versão final, define que o sujeito é constituído pelos três registros - o imaginário, o simbólico e o real. Em uma análise mais recente sobre o tema, Jorge (2017) caracteriza o imaginário como o campo do sentido, que é pleno e sem furos; o simbólico, como duplo sentido, referente ao inconsciente como linguagem e exemplificado pelo caráter metafórico dos sonhos e dos sintomas; e o real, como o registro referente à falta de sentido, como um furo no simbólico. Cabas (2010) representa o real como um obstáculo, como uma pedra no caminho à simbolização, como "um 'isso' que surge abrupto e que se opõe ao entendimento" (p.202), e o percurso da análise se dirige justamente ao encontro do analisante com esse real que o determina.

No entanto, é importante destacar que esses três campos, abordados extensivamente no decorrer do ensino de Lacan e também desdobrado por autores contemporâneos, todos eles são conexos, podendo ser conceituados apenas em sua inter-relação. Como foi falado anteriormente, o registro imaginário só é definido em virtude de uma influência do simbólico, e é só por meio deste, do simbólico, que o sujeito tem acesso ao real, "o sujeito só surge no mundo porque o significante aporta o traço mínimo que permite dizer que não há nada" (Tendlarz, 2010, p. 85).

$\mathrm{Na}$ mesma direção, o grafo do desejo se apresenta como uma estrutura que se remete à nodulação indissolúvel entre R.S.I. na constituição do sujeito, em que nenhum registro pode ser 
isolado. Como exemplo, Alfredo Eidelszein (2005) afirma que a estrutura do grafo não é planar, descontínua, mas que os elementos das duas superfícies se apresentam em contiguidade, fazendo com que haja uma relação encadeada nos dois patamares do grafo. Para ele, mesmo estando em andares separados, é razoável que a voz se junte ao gozo, já que aquela é objeto de gozo, e que a castração esteja em continuidade com o significante, visto que ela é justamente efeito deste último. A solução para resolver esta aparente separação é a noção lacaniana de oito interior ou volta dupla (em francês double boucle), que consiste em ligar as duas extremidades de uma fita retangular e dobrar um círculo sobre o outro. Em decorrência da semi-torção realizada passa a ser necessário dar-se duas voltas para chegar ao mesmo lugar. Isso permite exemplificar a continuidade da cadeia inferior com a superior, de modo que uma não é sem a outra, sendo ambas interdependentes.

O grafo do desejo, como um oito interior, trata, portanto, da relação contínua entre necessidade, demanda e desejo, sendo a demanda simbólica situada como a torção de um oito interior no plano da necessidade, que permite situar esta última como o seu aquém, e produzir o seu mais além, o desejo.

\section{Referências}

Bernardes, A. C. (1999). Sujeito suposto saber e dialética do desejo. In: O desejo é o diabo: as formações do inconsciente em Freud e Lacan. Rio de Janeiro, RJ: Contra Capa.

Cabas, A. G. (2010). O sujeito na psicanálise de Freud a Lacan: da questão do sujeito ao sujeito em questão. Rio de Janeiro, RJ: Jorge Zahar.

Clavurier, V. (2010). Réel, symbolique, imaginaire: du repère au noeud. Essaim, 25, 83-86.

Jorge, M. A. C. (2000). Fundamentos da psicanálise de Freud a Lacan - v.1: as bases conceituais. Rio de Janeiro, RJ: Jorge Zahar.

Jorge, M. A. C. (2010). Fundamentos da psicanálise de Freud a Lacan - v.2: a clínica da fantasia. Rio de Janeiro, RJ: Jorge Zahar.

Jorge, M. A. C. (2017). Fundamentos da psicanálise de Freud a Lacan - v.3: a prática analítica. Rio de Janeiro, RJ: Jorge Zahar.

Eidelszein, A. (2005). El grafo del deseo. Buenos Aires, Argentina: Letra Viva.

Fink, B. (1998). O sujeito lacaniano: entre a linguagem e o gozo. Rio de Janeiro, RJ: Jorge Zahar.

Freud, S. (1998a). Tres ensayos de teoría sexual. In S. Freud Obras completas (Jose L. Etcheverry, trad., Vol. 7, pp. 109-224). Buenos Aires, Argentina: Amorrortu Editores (trabalho original publicado em 1905).

Freud. (1998b). Introducción del narcisismo. In S. Freud Obras completas (Jose L. Etcheverry, trad., Vol. 14, pp. 65-98). Buenos Aires, Argentina: Amorrortu Editores (trabalho original publicado em 1914).

Iglesias, E. L. (1996). Aspectos topológicos do grafo do desejo. Cógito, 1, 29-33. Recuperado de $\quad$ http://pepsic.bvsalud.org/scielo.php?script=sci_arttext\&pid=S1519$\underline{94791996000100006 .}$ 
Lacan, J. (1953). O Simbólico, o Imaginário, o Real. Biblioteca Jacques Lacan. Recuperado de http://psicoanalisis.org/lacan/rsi-53.htm.

Lacan, J. (1976). Conférences et entretiens dans des universités nord-américaines. In Scilicet 6/7. Paris: Seuil.

Lacan, J. (1985). O seminário, livro 2: O eu na teoria de Freud e na técnica da psicanálise. (V. Ribeiro, trad.). Rio de Janeiro, RJ: Jorge Zahar. (Apresentação oral em 1954-55).

Lacan, J. (1991). O seminário, livro 7: A ética da psicanálise. (A. Quinet, trad.). Rio de Janeiro, RJ: Jorge Zahar. (Apresentação oral em 1959-60).

Lacan, J. (1992). O seminário, livro 8: A transferência. (D. D. Estrada, trad.). Rio de Janeiro, RJ: Jorge Zahar. (Apresentação oral em 1960-61).

Lacan, J. (1995). Algumas reflexões sobre o eu. Papéis: boletim interno do Corpo Freudiano, 2, 31-45 (Trabalho original publicado em 1951).

Lacan, J. (1995a). O seminário, livro 4: A relação de objeto. (D.D. Estrada, trad.). Rio de Janeiro, RJ: Jorge Zahar. (Apresentação oral em 1956-57).

Lacan, J. (1999). O seminário, livro 5: As formações do inconsciente. (V. Ribeiro, trad.). Rio de Janeiro, RJ: Jorge Zahar. (Apresentação oral em 1957-58).

Lacan, J. (1998a). O estádio do espelho como formador da função do eu tal como nos é revelada na experiência psicanalítica. In. J. Lacan, Escritos. (V. Ribeiro, trad., pp. 96-103). Rio de Janeiro, RJ: Jorge Zahar. (Trabalho original publicado em 1949).

Lacan, J. (1998b). A coisa freudiana. In. J. Lacan, Escritos. (V. Ribeiro, trad., pp. 402-437). Rio de Janeiro, RJ: Jorge Zahar. (Trabalho original publicado em 1955).

Lacan, J. (1998c). O seminário sobre a carta roubada. In. J. Lacan, Escritos. (V. Ribeiro, trad., pp. 13-66). Rio de Janeiro, RJ: Jorge Zahar. (Trabalho original publicado em 1956).

Lacan, J. (1998d). A instância da letra no inconsciente ou a razão desde Freud. In. J. Lacan, Escritos. (V. Ribeiro, trad., pp. 496-533). Rio de Janeiro, RJ: Jorge Zahar. (Trabalho original publicado em 1957).

Lacan, J. (1998e). A direção do tratamento e os princípios de seu poder. In. J. Lacan, Escritos. (V. Ribeiro, trad., pp. 591-652). Rio de Janeiro, RJ: Jorge Zahar. (Trabalho original publicado em 1958).

Lacan, J. (1998f). Subversão do sujeito e dialética do desejo no inconsciente freudiano. In. J. Lacan, Escritos. (V. Ribeiro, trad., pp. 807-842). Rio de Janeiro, RJ: Jorge Zahar. (Trabalho original publicado em 1960).

Lacan, J. (1998g). Posição do inconsciente no Congresso de Bonneval. In. J. Lacan, Escritos. (V. Ribeiro, trad., pp. 843-864). Rio de Janeiro, RJ: Jorge Zahar. (Trabalho original publicado em 1964 [1960]).

Lacan, J. (2003). Radiofonia. In. J. Lacan, Outros Escritos. (V. Ribeiro, trad., pp. 400-447). Rio de Janeiro, RJ: Jorge Zahar. (Trabalho original publicado em 1970).

Lacan, J. (2005). O seminário, livro 10: A angústia. (V. Ribeiro, trad.). Rio de Janeiro, RJ: Jorge Zahar. (Apresentação oral em 1962-63).

Lacan, J. (2007). O seminário, livro 23: o sinthoma. (S. Laia, trad.). Rio de Janeiro, RJ: Jorge Zahar. (Apresentação oral em 1975-76). 
Lacan, J. (2008). O seminário, livro 11: os quatro conceitos fundamentais da psicanálise. (M. D. Magno, trad.). Rio de Janeiro, RJ: Jorge Zahar. (Apresentação oral em 1964).

Lacan, J. (2016). O seminário, livro 6: O desejo e sua interpretação. (C. Berliner, trad.). Rio de Janeiro, RJ: Jorge Zahar. (Apresentação oral em 1958-59).

Lacan, J. (n.d). seminário 22: R.S.I. Versión completa de la Escuela Freudiana de Buenos Aires (Apresentação oral em 1974-75).

Laplanche, J.; Pontalis, J. B. (2004). Vocabulário da Psicanálise. (P. Tamen, trad.) São Paulo, SP: Martins Fontes.

Ogilvie, B.(1991). Lacan: a formação do conceito de sujeito. Rio de Janeiro, RJ: Jorge Zahar.

Roudinesco, E. (2006). A análise e o arquivo. Rio de Janeiro, RJ: Jorge Zahar.

Saussure, F. (2004). Curso de linguística geral. São Paulo, SP: Cultrix.

Sirelli, N. M. (2010). Alienação e separação: a lógica do significante e do objeto na constituição do sujeito. (Dissertação de Mestrado, Programa de Pós-Graduação em Psicologia, Instituto de Psicologia, Universidade Federal de São João del- Rei).

Tendlarz, S. E. (2001). R.S.I.: el falo. Buenos Aires: ICBA.

Wallon, H. (1971). As origens do caráter da criança. São Paulo, SP: Difusão Europeia do Livro.

Wine, N. (1992). Pulsão e inconsciente: a sublimação e o advento do sujeito. Rio de Janeiro, RJ: Jorge Zahar.

Žižek, S. (1992). Eles não sabem o que fazem: o sublime objeto da ideologia. Rio de Janeiro, RJ: Jorge Zahar.

Revisão gramatical: Claudio Cedamanos

E-mail: claudio.cedamanos@hotmail.com

Recebido em setembro de 2020 - Aceito em março de 2021. 